ABCD Arq Bras Cir Dig

2019;32(2):e1444

DOI: /10.1590/0102-672020180001e1444

\section{CYSTOGASTROSTOMY WITH ARGON PLASMA COAGULATION PROBE AND WITHOUT ENDOSCOPIC ULTRASONOGRAPHY}

\section{Cistogastrostomia com sonda de coagulação de plasma de} argônio e sem ultrassonografia endoscópica

Omer Faruk OZKAN ${ }^{1}$, Erdem AKBAL ${ }^{1}$, Sukru TAS ${ }^{2}$, Fahri GUNES

How to cite this article: Ozkan OF, Akbal E, Tas $S$, Gunes $F$. Cystogastrostomy with argon plasma coagulation probe and without endoscopic ultrasonography. ABCD Arq Bras Cir Dig. 2019;32(2):e1444. DOI: /10.1590/0102-672020180001e1444

From the ${ }^{1}$ Department of General Surgery; ${ }^{2}$ Department of Gastroenterology; ${ }^{3}$ Department of Internal Medicine, Çanakkale Onsekiz Mart University, Çanakkale, Turkey.

\section{Correspondência:}

Omer F. Ozkan

Email: ozkanfomer@gmail.com

HEADINGS - Argon Plasma Coagulation, Ultrasonography, Gastrostomy DESCRITORES - Coagulação com Plasma de Argônio, Ultrassonografia, Gastrostomia

Financial source: none

Conflict of interest: none

Received for publication: 01/04/2017

Accepted for publication: 06/02/2019

\section{INTRODUCTION}

A cute pancreatitis is an inflammatory condition of the pancreas which can lead to morbidity. Formation of pancreatic pseudocyst is one of the well-known complication. While small pseudocyts are asymptomatic, large ones can become symptomatic and cause several complications including infection, rupture, bleeding, biliary complications and portal hypertension ${ }^{1,2}$.

Various interventions are available for the management of symptomatic pancreatic pseudocysts. Endoscopic ultrasound (EUS) guided cystogastrostomy is a choice for treatment of large pseudocyts, witch bulge into gastric lumen ${ }^{2,3}$. In this paper we present a case of large sized who was managed with argon plasma coagulation probe and without endoscopic ultrasonography.

\section{CASE REPORT}

Fifty years old male was in reanimation clinic with the diagnosis of complicated and severe acute pancreatitis due to gallstones for three months. His physical examination revealed a large sized mass extending from epigastric to left upper quadrant of abdomen. The contrast enhanced CT showed a cystic lesion with $150 \times 100 \mathrm{~mm}$ dimensions in the tail and body of pancreas pushing the stomach (Figure1). The diagnostic upper gastrointestinal endoscopy revealed a bulge localized on large curvature related to pancreatic pseudocyst. An endoscopic cystogastrostomy was planned. After detection of the area for cytogastrostomy in gastric lumen with standard video-endoscope (Pentax EG 290 LK), it was marked by argon plasma coagulation probe (30 watt); the gastric wall was opened step-by-step with the probe ( 60 watt) until pancreatic fluid drainage into stomach was seen. After aspiration of pancreatic fluid (approximately $1500 \mathrm{ml}$ ), the gastric opening area enlarged by using an ERCP sphincterotomy. Then a guide wire was inserted into the cyst with the $\mathrm{C}$ arm fluoroscopy. Finally, $8.5 \mathrm{~F}$ pigtail plastic stent was placed into the cyst through the gastric lumen. The procedure was completed without any complication.

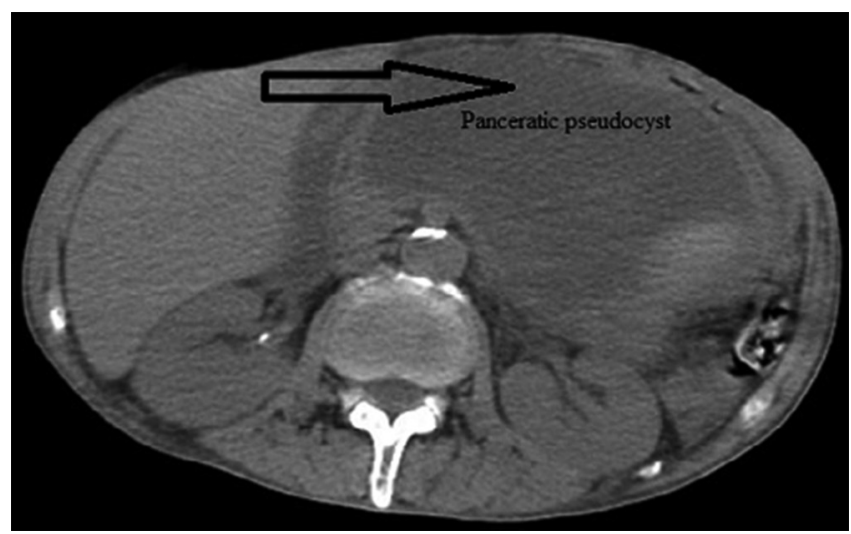

FIGURE1 - Pancreatic pseudocyst with 150x100 mm pushing gastric wall

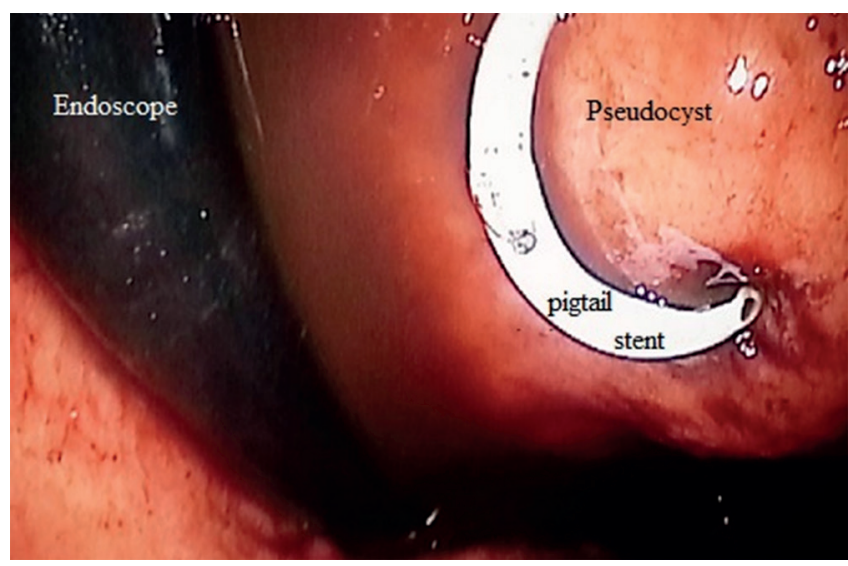

FIGURE 2 - Plastic pigtail stent installed with argon plasma coagulation probe cut

\section{DISCUSSION}

EUS guided cystogastrostomy is a safe method formanagement of pancreatic pseudocyts ${ }^{1,3}$. EUS assisted cytogastrostomy has a significant advantage by providing relation between cyst wall and gastric wall, cyst fluid imaging features, and gastric wall vessels ${ }^{2}$. If pseudocysts have a bulge through the gastric lumen, cytogastrostomy can be performed without EUS. To avoid the complications such as bleeding, cystogastrostomy was performed by an argon plasma coagulation probe ${ }^{2,3}$. In the literature, EUS with cytogastrostomy procedures usually performed with needle knife and YAG laser ${ }^{4}$

Our case has demonstrated that argon plasma coagulation without endoscopic ultrasonography cytogastrostomy can be an option in handling large volume pancreatic pseudocyst during endoscopic cystogastrostomy. 


\section{ORCID}

Omer F. Ozkan: 0000-0002-6644-2413

\section{REFERENCES}

1. Ake Andrén-Sandberg, Christos D. Pancreatic pseudocysts in the 21st century. Part II: Natural history. JOP 2004; 5: 64-70.

2. Buchi KN, Bowers JH, Dixon JA. Endoscopic pancreatic cystogastrostomy using the Nd: YAG laser. Gastrointest Endosc. 1986;32:112-114.

3. LopesCV,PesentiC,BoriesE,CaillolF,Giovannini.M.Endoscopic-ultrasoundguidedendoscopic transmural drainage of pancreatic pseudocysts and abscesses. Scand J Gastroenterol.2007;42:524-529.

4. Rasmussen DN,Hassan H,Vilmann P. Only few severe complications after endoscopic ultrasoundguideddrainage of pancreatic pseudocysts. Dan Med J.2012;59:A4406. 